\title{
Combined endoscopic repair of the mitral and tricuspid valve
}

\author{
Jeffrey Shuhaiber
}

Massachusetts General Hospital, Wellman Institute, Boston, MA, USA

Correspondence to: Jeffrey Shuhaiber. Massachusetts General Hospital, Wellman Institute, Thier Bldg. 50 Blossom St., Boston, MA 02114, USA. Email: Jeffrey.Shuhaiber@gmail.com.

Comment on: Huang LC, Xu QC, Chen DZ, et al. Hospital outcome of concomitant tricuspid annuloplasty during totally endoscopic mitral valve surgery: a propensity matched study. J Thorac Dis 2021;13:3042-50.

Submitted May 01, 2021. Accepted for publication Jul 30, 2021.

doi: $10.21037 /$ jtd-2021-16

View this article at: https://dx.doi.org/10.21037/jtd-2021-16

The great artist Michelangelo once said, "The greater danger for most of us lies not in setting our aim too high and falling short, but in setting our aim too low, and achieving our mark."

Aiming high is risk-taking yet a reflection of thinking big. Aiming higher than the current status empowers us to perform more creatively and potentially effectively, overcoming challenges while creating opportunities. It builds resilience and acknowledges weaknesses in the operator and the team while recognizing what could be further achieved. Relentless practice in addition to talent allows high aims to be achieved. It produces positive energy outweighing negativity and confinement. The journey of cardiac surgery has been full of innovation, and the story continues in this article.

Huang et al. are to be congratulated on achieving excellent outcomes by endoscopic repair of the tricuspid and mitral valve (1). The tricuspid valve was ignored more than the mitral valve yet now more recognized as a vital heart valve and surgically accessible right-sided valve endoscopically. Functional tricuspid regurgitation is the most common form of the disease. In the absence of severe tricuspid valve insufficiency, separating tricuspid—related symptoms from mitral valve-related symptoms is difficult. Echocardiography can gauge the severity of the tricuspid valve in relation to predicted pulmonary artery pressures and heart function, and in conjunction with patient clinical assessment can be quite comprehensive. Suppose suspicion is high that tricuspid valve insufficiency is significant, in that case, there is nothing wrong with addressing the tricuspid valve at the time of mitral valve surgery by opening the right atrium. The authors did just that using a trans- septal approach, gauging the annulus dilation using a rigid annuloplasty sizer after closing the septum and repairing the mitral valve. While this approach is often performed less than direct atrial chamber opening with excellent echocardiography imaging and interpretation, the surgeon made the final determination as to repair the tricuspid valve. Tricuspid valve repair was performed without excluding the vena cava and yet with careful adjustment of the single femoral venous two-stage cannula, which can be unreliable and time-consuming to optimize venous return. Tricuspid annuloplasty was done using both a suture or ring. Cumulative evidence portends that ring prosthesis is durably more superior to suture annuloplasty by optimizing tricuspid leaflet coaptation (2). Furthermore, rigid ring is superior to flexible ring (2). This is important since mortality and morbidity have been linked to tricuspid valve severity and residual regurgitation after mitral valve surgery (2). Their procedure time, outcomes, and follow-up are excellent. Interestingly, a recent meta-analysis of secondary tricuspid valve insufficiency showed that mortality was similar for both suture and ring annulopasty (2).

There have been several guidelines published regularly from both North American and European policies. The overarching consensus about as to when to intervene on the tricuspid valve at the time of mitral valve surgery is based on symptoms, annulus dilation $\left(40 \mathrm{~mm}\right.$ or $\left.21 / \mathrm{mm}^{2}\right)$, grade right ventricular dysfunction with associated pulmonary artery pressures (3). The authors followed these guidelines.

Furthermore, the authors used a 1:1 matching propensity score to achieve 40 matched pairs to attain similar pathophysiological variables for fair comparison of 
those with mitral valve surgery alone versus mitral valve and tricuspid valve surgery. It is unclear how a decision in avoiding to repair tricuspid valve regurgitation (moderate plus) at the time of mitral valve surgery was made. Nonetheless, the authors used this data for comparison and found that adding tricuspid valve repair in their hands was feasible and safe.

There are three general approaches to propensity score matching: stratification of the entire population into quintiles based on the propensity score and comparing the treatment received conditions (Mitral vs. Mitral and Tricuspid annuloplasty) within each quintile, matching each treatment of interest patient (in this paper combined Mitral and tricuspid repair) with 1,2 , or 3 controls (mitral repair only patients) and using the propensity score as a covariate in a regression model.

Following Rosenbaum and Rubin (4), and Rubin (5), the first approach (stratification into quintiles) is the method of choice when sample sizes are large enough in both groups to permit such an analysis; otherwise, the authors should have considered the second approach $(1: 1$ or $1: 2$ or $1: 3$ matching) instead of just holding to 1:1 matching. Perhaps the authors could have extended their matching to up to 3 matching patients assuming the data would be available. The third strategy (i.e., using the propensity score as a covariate) should generally not be conducted because it makes the strong assumption of linearity of the relationship between the propensity score and the outcome variable of interest. There is no way to directly examine the possibility that the patient characteristics and treatment conditions are completely confounded (i.e., no overlap in potential confounder distributions between treatment and control conditions).

The authors have elevated the surgical standards through this report and we look forward to long-term follow-up data in the years to come. However, tricuspid transcatheter approaches both at the annulus repair and leaflet coaptation level are finding their way and wanting to leave their mark $(6,7)$. Transcatheters aim to overcome the challenges with open surgery, mainly when patients are not optimal surgical candidates. Transcatheters valves are the ultimate minimally invasive procedures and encouraged in this difficult population. Aiming high is here to stay, and we look forward to the journey of innovation in heart valve surgery.

\section{Acknowledgments}

Funding: None.

\section{Footnote}

Provenance and Peer Review: This article was commissioned by the editorial office, Fournal of Thoracic Disease. The article did not undergo external peer review.

Conflicts of Interest: The author has completed the ICMJE uniform disclosure form (available at https://dx.doi. org/10.21037/jtd-2021-16). The author has no conflicts of interest to declare.

Ethical Statement: The author is accountable for all aspects of the work in ensuring that questions related to the accuracy or integrity of any part of the work are appropriately investigated and resolved.

Open Access Statement: This is an Open Access article distributed in accordance with the Creative Commons Attribution-NonCommercial-NoDerivs 4.0 International License (CC BY-NC-ND 4.0), which permits the noncommercial replication and distribution of the article with the strict proviso that no changes or edits are made and the original work is properly cited (including links to both the formal publication through the relevant DOI and the license). See: https://creativecommons.org/licenses/by-nc-nd/4.0/.

\section{References}

1. Huang LC, Xu QC, Chen DZ, et al. Hospital outcome of concomitant tricuspid annuloplasty during totally endoscopic mitral valve surgery: a propensity matched study. J Thorac Dis 2021;13:3042-50.

2. Veen KM, Etnel JRG, Quanjel TJM, et al. Outcomes after surgery for functional tricuspid regurgitation: a systematic review and meta-analysis. Eur Heart J Qual Care Clin Outcomes 2020;6:10-8.

3. Baumgartner H, Falk V, Bax JJ, et al. 2017 ESC/EACTS Guidelines for the management of valvular heart disease. Eur Heart J 2017;38:2739-91.

4. Rosenbaum PR, Rubin DB. The Central Role of the Propensity Score in Observational Studies for Causal Effects. Biometrika 1983;70:41-50.

5. Rubin DB. On principles for modeling propensity scores in medical research. Pharmacoepidemiol Drug Saf 2004;13:855-7.

6. Latib A, Agricola E, Pozzoli A, et al. First-in-Man Implantation of a Tricuspid Annular Remodeling Device 
for Functional Tricuspid Regurgitation. JACC Cardiovasc Interv 2015;8:e211-4.

7. Braun D, Nabauer M, Orban M, et al. One-year results of transcatheter treatment of severe tricuspid regurgitation using the edge-to-edge repair technique. EuroIntervention 2018;14:e413-5.

Cite this article as: Shuhaiber J. Combined endoscopic repair of the mitral and tricuspid valve. J Thorac Dis 2021;13(8):46264628. doi: 10.21037/jtd-2021-16 